\title{
Human rights, political instability and investment in South Africa: a note
}

\author{
David Fielding, \\ Department of Economics, University of Leicester \\ and Centre for the Study of African Economies, University of \\ Oxford*
}

WPS/2001.4

\begin{abstract}
This paper extends the model of Fielding (1999), which is designed to explain changes in investment in South Africa during the Apartheid period, by allowing a role for indicators of political instability and political and civil rights, as measured by Fedderke et al. (1999). The conclusions based on estimation of the original model are robust to the inclusion of the political factors, but these factors do explain some of the variation in investment over time.
\end{abstract}

JEL Classification: E22; O16

Keywords: Investment, Social Capability, South Africa

* Address for correspondence: Department of Economics, University of Leicester, Leicester LE1 7RH, UK. E-mail: DJF14@LE.AC.UK; Fax: +44-116-252-2908; Telephone: +44-116-252-3909. 


\section{Introduction}

Fielding (1999) presented a time-series model of South African investment for 1960-93 in which the aggregate capital stock in the manufacturing sector is explained by the user cost of capital, real wages, the scale of output and several indicators of economic uncertainty. The relative sizes of the estimated coefficients lead to a number of conclusions about the constraints facing South African investors, as well as about the relative importance of different types of economic uncertainty.

In the same year, Fedderke et al. (1999) presented time series measures of a number of variables designed to capture elements of social capability in South Africa over the period 1935-97. These include indicators of political instability, political rights and civil (property) rights. ${ }^{1}$ It is suggested that these variables can explain some of the variation in South African economic performance over time, just as cross-country measures of social capability can explain variations in economic performance across countries (Johnson and Temple, 1998; Fedderke and Klitgaard, 1998). These cross-country studies suggest that social capability plays an important role in the growth process, but cross-country variations in social capability measures cannot easily be linked directly to public policy changes. This limitation is not true of time-series variations, so time-series models potentially have more to say that is of interest to the policy-maker.

In this paper we present an extension of the Fielding (1999) model of investment that includes measures of social capability from the Fedderke et al. (1999) paper. The purpose of this exercise is twofold: first, to determine whether the conclusions based on the original estimates of the investment equations are robust to the inclusion of social capability measures; and second, to see whether the investment data can support Fedderke et al.'s suggestion that time-series variations in social capability can affect economic performance in an individual country.

\section{The Revised Model}

The regression estimates presented below are revisions of the original model of the capital stock summarised by Fielding (1999)'s equation (14), which is:

$$
\begin{aligned}
\ln \left(k_{t}\right)= & \Sigma_{i} b_{i} \ln \left(k_{t-i}\right)+\Sigma_{j} a_{1, j} D(j)+a_{2} \ln (c / P)_{t}+a_{3} \ln (w / P)_{t}+a_{4} \ln (g)_{t}+a_{5} \ln (Q)_{t} \\
& +a_{6} S(1)_{t}+a_{7} S(2)_{t}+a_{8} S(3)_{t}+a_{9} m_{t}+a_{10} f(t)+u_{t}
\end{aligned}
$$

$k$ is the private manufacturing capital stock, the $D(j)$ are seasonal dummies, $c / P$ is the real user cost of capital, $w / P$ is the real wage rate, $g$ is the public capital stock, $Q$ is a measure of output per firm, the $S($.) are indicators of uncertainty in the net returns to investment, $m$ is an indicator of macroeconomic instability (in the reported regressions a long-short interest rate spread, $\left.\left[r_{B}-r_{T}\right]\right), f(t)$ is a time trend and $u$ an i.i.d. residual. To this equation we add three variables from Fedderke et al. (1999): the 0-200 index of political freedom, POR (in Appendix 1 of the paper), the 0-100 index of property rights, PRR (in Appendix 2) and the "consensus" index of political instability, INS (on page 24). Fedderke et al. explain the policy changes that led directly or indirectly to variations in the three series. We do not reproduce the explanations here, but note that the changes are largely policy-driven.

The regression equations reported below employ the same quarterly economic data as in Fielding (1999). The three political variables are reported only anually, so we construct quarterly interpolations using the method of Lisman and Sandee (1963). All of the economic variables appear to be $\mathrm{I}(0)$ except for $\ln (g)$, which appears to be I(1); so this variable appears in

\footnotetext{
${ }^{1}$ See Fedderke et al. (1999, Section 5) for definitions of these political concepts.
} 
the regression equations in first differences. Fedderke and Liu (1999) report tests for the order of integration of a range of the political variables from the Fedderke et al. (1999) paper. They cannot in any case reject the null that the series are I(1), but note that their tests have low power because of the many possible structural breaks that might have arisen in the political turbulence of Apartheid South Africa. In the regression equations below the political variables appear in first differences. Levels of the variables, when added to these regressions, have no explanatory power. ${ }^{2}$

Table 1 reports the results of estimating the revised capital stock equation by IV without any restrictions; it corresponds to Table 3 in Fielding (1999), with impact elasticities on explanatory variables reported above steady-state elasticities. As in the original version of the model nine lags of the dependent variable are included, and $\ln (c / P), \ln (w / P)$ and $\ln (Q)$ are instrumented on their own lagged values. Comparison of the two tables shows that none of the coefficients in the original version of the model is significantly different from its counterpart in Table 1 below; t-ratios are slightly lower in the revised model, but this would not affect statistical inference if a generous confidence interval were used. The rank ordering of variables by the size of their coefficients is unchanged, and therefore the economic inferences presented in Fielding (1999) are robust to the inclusion of the political variables. All these remarks are still true if we estimate a restricted version of the model in which some variables are omitted so as to minimize the Schwartz Bayesian Information Criterion. This version is reported in Table 2, which corresponds to Table 4 of Fielding (1999). Recursive estimates of the model (available on request) indicate that there is no significant variation in the regression coefficients as the sample size changes.

Two of the three political variables are statistically significant at the $5 \%$ level: INS (political instability) and PRR (property rights). Increases in instability reduce the capital stock and improvements in property rights raise the capital stock. It is not possible at this degree of aggregation to determine whether these effects reflect a link between perceived investment risk and political instability / poor property rights, or whether these factors reduce the return to capital by inhibiting efficient capital allocation. Nevertheless, the political variables do explain some of the variation in the capital stock over time that was previously unexplained.

The estimated steady-state coefficent on the rate of growth of the PRR index is 0.408 . This coefficient implies that changes in the property rights series have a marked impact on the capital stock. Between 1977 (the political low point of the Apartheid era) and 1997, PRR grew by $1.4 \%$ per quarter. The regression coefficient implies that during this transition period the steady-state capital stock was on average $0.57 \%$ higher than it would otherwise have been. This $0.57 \%$ is equivalent to 0.92 billion Rand at 1995 prices. Similarly, the regression coefficient on $\triangle I N S(-0.27)$ implies that over the two years of the sharpest rise in the instability index (by around 3,000 points between 1985 and 1987) the steady-state capital stock was $1.02 \%$ lower than it would otherwise have been. ${ }^{3}$

2 The regression includes growth rates of POR and PRR; this is not possible for INS, which is sometimes equal to zero, so absolute changes in INS are used.

${ }^{3}$ To put these numbers in context, the sample standard deviation of $\triangle \ln (P R R)$ is $3.36 \%$, and that of $\triangle I N S^{*} 0.0001$ is $2.41 \%$. 
Table 1: Modified Capital Stock Equation (1): IV Estimates [1963(1)-1993(4)]

\begin{tabular}{|c|c|c|c|}
\hline Variable & Coeff. & Std. Err. & $t$ ratio \\
\hline $\ln (Q)$ & 0.06868 & 0.03935 & 1.745 \\
\hline $\ln (\mathrm{C} / \mathrm{P})$ & -0.03525 & 0.01451 & -2.429 \\
\hline $\ln (w / P)$ & -0.17026 & 0.10380 & -1.640 \\
\hline$\Delta \ln (\mathrm{g})$ & -0.06195 & 0.14937 & -0.415 \\
\hline$\left[r_{\mathrm{B}}-r_{\mathrm{T}}\right]$ & -0.47088 & 0.17107 & -2.753 \\
\hline$S(1)$ & 0.54496 & 0.40911 & 1.332 \\
\hline$S(2)$ & 0.09181 & 0.55716 & 0.165 \\
\hline$S(3)$ & -0.13181 & 0.69251 & -0.190 \\
\hline$\Delta \ln (\mathrm{POR})$ & 0.02883 & 0.03033 & 0.951 \\
\hline$\triangle \ln (\mathrm{PRR})$ & 0.14752 & 0.06071 & 2.430 \\
\hline$\triangle I N S * 0.0001$ & -0.09797 & 0.04662 & \\
\hline $\mathrm{D}(1)$ & 0.01698 & 0.00920 & 1.845 \\
\hline $\mathrm{D}(2)$ & 0.01097 & 0.01006 & 1.090 \\
\hline$D(3)$ & 0.00458 & 0.00723 & 0.634 \\
\hline
\end{tabular}

Solved long run equation

\begin{tabular}{lccr} 
Variable & Coeff. & Std. Err. & \multicolumn{1}{c}{ ratio } \\
$\ln (\mathrm{Q})$ & 0.1899 & 0.0939 & 2.022 \\
$\ln (\mathrm{C} / \mathrm{P})$ & -0.0975 & 0.0496 & -1.966 \\
$\ln (\mathrm{w} / \mathrm{P})$ & -0.4709 & 0.2787 & -1.690 \\
$\triangle \ln (\mathrm{g})$ & -0.1713 & 0.4143 & -0.413 \\
{$\left[r_{\mathrm{B}}-r_{\mathrm{T}}\right]$} & -1.3020 & 0.5210 & -2.499 \\
$\mathrm{~S}(1)$ & 1.5070 & 1.0910 & 1.381 \\
$\mathrm{~S}(2)$ & 0.2539 & 1.5340 & -0.166 \\
$\mathrm{~S}(3)$ & -0.3646 & 1.9280 & -0.189 \\
$\triangle \ln (\mathrm{POR})$ & 0.0797 & 0.0883 & 0.903 \\
$\triangle \ln (\mathrm{PRR})$ & 0.4080 & 0.2022 & 2.018 \\
$\triangle \mathrm{INS} 0.0001$ & -0.2709 & 0.1482 & -1.828 \\
$\mathrm{D}(1)$ & 0.0470 & 0.0270 & 1.741 \\
$\mathrm{D}(2)$ & 0.0303 & 0.0277 & 1.094 \\
$\mathrm{D}(3)$ & 0.0127 & 0.0200 & 0.635
\end{tabular}

IV specification test $: x \bullet(24)=28.755 \quad[0.2295]$ RSS $=0.0270$

LM residual autocorrelation (order 1$): F(1,97)=0.34524$ [0.5582]

LM residual autocorrelation (order 4): $F(4,94)=0.21256$ [0.9309]

LM Heteroscedasticity: $F(47,50)=0.85508$ [0.7049]

LM ARCH (order 1): $F(1,96)=1.0689$ [0.3038]

LM ARCH (order 4): $F(4,90)=0.6324$ [0.6407]

Residual normality: $x \bullet(2)=0.7314$ [0.6937] 


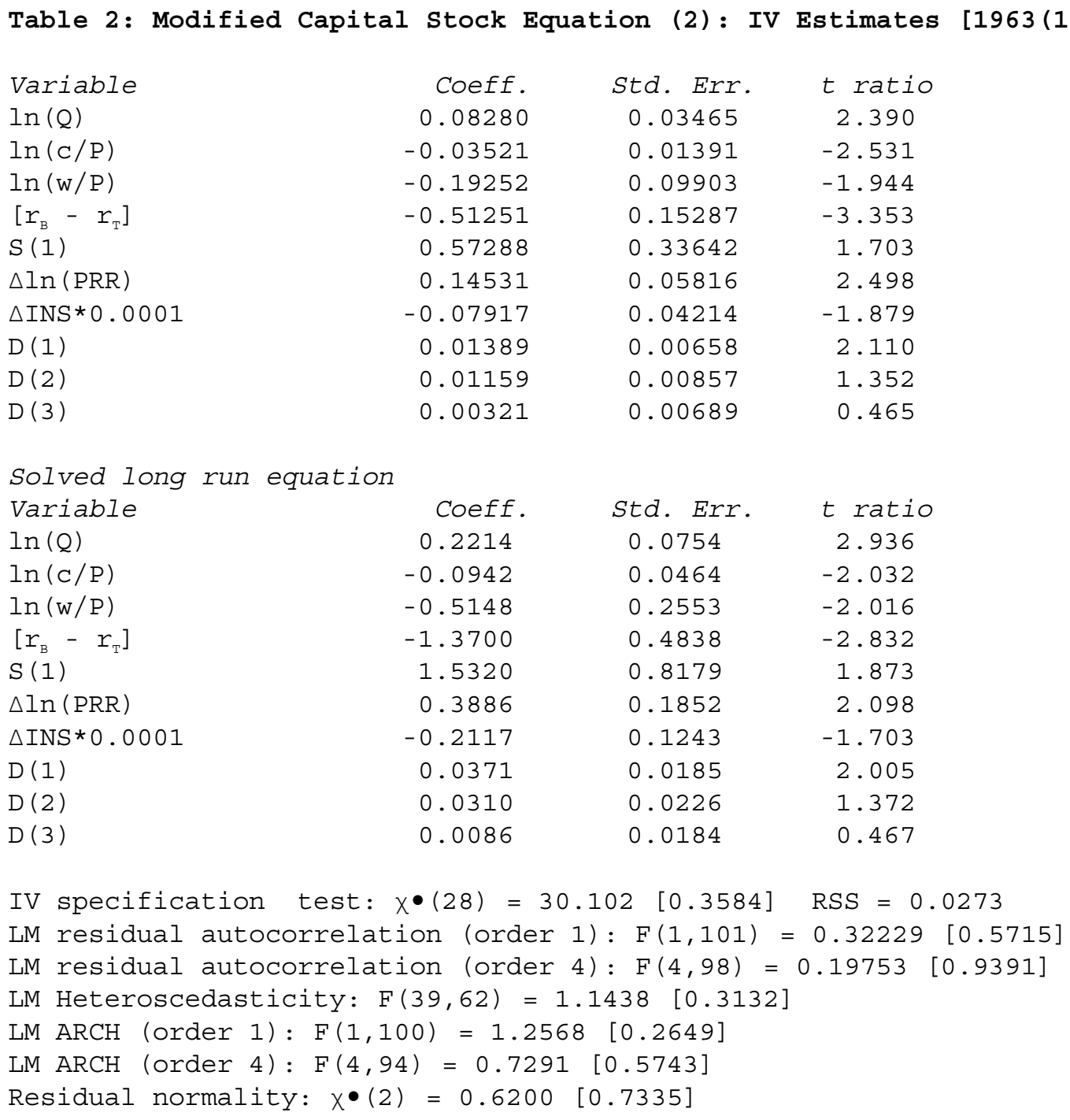

\section{Conclusion}

We have shown that manufacturing investment in South Africa is highly sensitive to timevarying measures of the state of the South African polity, as well as to indicators of economic uncertainty. The addition of the political variables does not alter previous conclusions about the economic determinants of investment, but the political factors do explain some of the variance in investment performance over time that was previously unexplained. During the period of political liberalization South African investment performance has been better than could otherwise have been expected.

\section{References}

Fedderke, J. and Klitgaard, R. (1998) "Economic Growth and Social Indicators: An Exploratory Analysis", Economic Development and Cultural Change, 46, 455-90

Fedderke J., de Kadt, R. and Luiz, J. (1999) "Indicators of Political Liberty, Property Rights and Political Instability in South Africa: 1935-97", ERSA Working Paper 4, University of the Witwatersrand Fedderke, J. and Liu, W. (1999) "Modelling the Determinants of Capital Flows and Capital Flight: With an Application to South African Data for 1960-95", ERSA Working Paper 5, University of the Witwatersrand 
Fielding, D. (1999) "Manufacturing Investment in South Africa: A Time-Series Model", Journal of Development Economics, 58, 405-27

Johnson, P. and Temple, J. (1998) "Social Capability and Economic Growth", Quarterly Journal of Economics, 113, 965-90

Lisman, J. and Sandee, J. (1963) "Derivation of Quarterly Figures from Annual Data", Journal of the Royal Statistical Society (Series C), 13, 87-90 